\title{
Neutral Current Ripple Minimization in a Three-Level Rectifier
}

\author{
Ashish Bendre, Member, IEEE, and Giri Venkataramanan, Member, IEEE
}

\begin{abstract}
This paper proposes a novel neutral-point voltage regulator for a three-level diode clamped rectifier that uses a fast space vector modulator in conjunction with a sharing function controller for neutral-point regulation. Redundant state choices are controlled via a continuous sharing function, and small signal models are developed for closed-loop regulators with this sharing function as the control variable. A significant improvement is seen in the voltage distortion at the neutral point when the regulator is used, and this leads to a definitive reduction in the required dc bus capacitance.
\end{abstract}

Index Terms-Control, inverters, modulation, multilevel, neutral, rectifiers.

\section{INTRODUCTION}

$\mathbf{T}$ HREE-LEVEL or neutral-point clamped converters are seeing increased application in industrial drive systems [1], [2]. Several carrier-based and space-vector-based modulation strategies are commonly used to synthesize waveforms using these converters [3], [4]. The modulators for these converters also need to regulate the neutral-point potential at the middle of the dc bus voltage from diverging due to asymmetries introduced by parasitic parameters like device voltage drops and modulator time delays. Both multiple carrier and nearest three vector (NTV) approaches lead to significant third harmonic injection into the neutral point of the converter. This causes an increase in the required dc link capacitance of the converter. While open loop strategies have been proposed for the reduction of the harmonic content [5], a closed-loop strategy that reduces the harmonic content of the neutral-point current is developed in this paper. Most approaches for performing this are based on complex heuristic control methods and/or lookup tables and hence do not have definitive performance levels.

Paper IPCSD-05-090, presented at the 2003 Industry Applications Society Annual Meeting, Salt Lake City, UT, October 12-16, and approved for publication in the IEEE TRANSACTIONS ON INDUSTRY APPLICATIONS by the Industrial Power Converter Committee of the IEEE Industry Applications Society. Manuscript submitted for review February 3, 2004 and released for publication December 8, 2005. This work was supported by the Wisconsin Electric Machines and Power Electronics Consortium (WEMPEC), by DRS Power and Control Technologies, and by the Office of Naval Research under Grant N00014-01-1-0623. This work also used shared facilities provided by the ERC Program of the National Science Foundation under Award Number EEC9731677 to the Center for Power Electronics Systems (CPES) at the University of Wisconsin, Madison.

A. Bendre is with the Advanced Development Group, DRS Power and Control Technologies, Milwaukee, WI 53216 USA (e-mail: ashishrbendre@ drs-pct.com).

G. Venkataramanan is with the Department of Electrical and Computer Engineering, University of Wisconsin, Madison, WI 53706 USA (e-mail: giri@engr.wisc.edu).

Digital Object Identifier 10.1109/TIA.2005.863902
Although modeling of this phenomenon has been carried out for the switching frequency effects of various modulators, averaged models to study these dependencies are just emerging [6]-[8]. This paper focuses on the design of closed-loop compensator for neutral-point regulation with space vector modulators.

The controller functions for generalized multilevel rectifier systems can be partitioned into two closed-loop regulators - one regulating the total dc-bus voltage and another that maintains the neutral-point potential at the middle of the dc stack. The dc-bus regulator generates a current reference that is proportional to the compensated dc voltage error signal, similar to more common two-level rectifier systems. The neutralpoint regulator is based on controlling the neutral-point current injection as a function of a control input that depends on the existing imbalance between the top and bottom sections of the dc stack. This paper is primarily concerned with the operation and design of the neutral-point regulator.

Small signal transfer function models are developed using switching function averaging approaches for the space vector modulator and used to design the neutral-point regulator. A detailed simulation of a three-level rectifier shows the benefits of using the closed-loop regulator for space vector modulation methods. The partitioning of three-level inverter controller functions into dc bus regulation and dc bus balance is described in Section II along with block diagrams of the neutral-point regulator. Section III presents the relationships between the neutral-point current injection and the control variables for the regulator. In Section IV, a linearized small signal model for the controller is presented while simulation results verifying the performance of the regulator are presented in Section V. Section VI contains selected results from a laboratory prototype rectifier used to verify the operation and stability of the system followed by conclusions and summary in Section VII.

\section{Neutral-Point Regulation}

The controller functions for generalized multilevel rectifier systems may be partitioned into two closed-loop regulators as illustrated in Fig. 1: a "sum" regulator that controls the total dc bus voltage and a "difference" regulator that controls the neutral-point voltage. The proposed control approach for regulating the neutral-point voltage of a three-level neutralpoint clamped inverter is based on the concept of "sharing function" introduced in [8]. A representation of the switching states available for synthesizing the output voltages using a three-level rectifier on the $(\mathrm{g}-\mathrm{h})$ plane is illustrated in Fig. 2 [4]. 


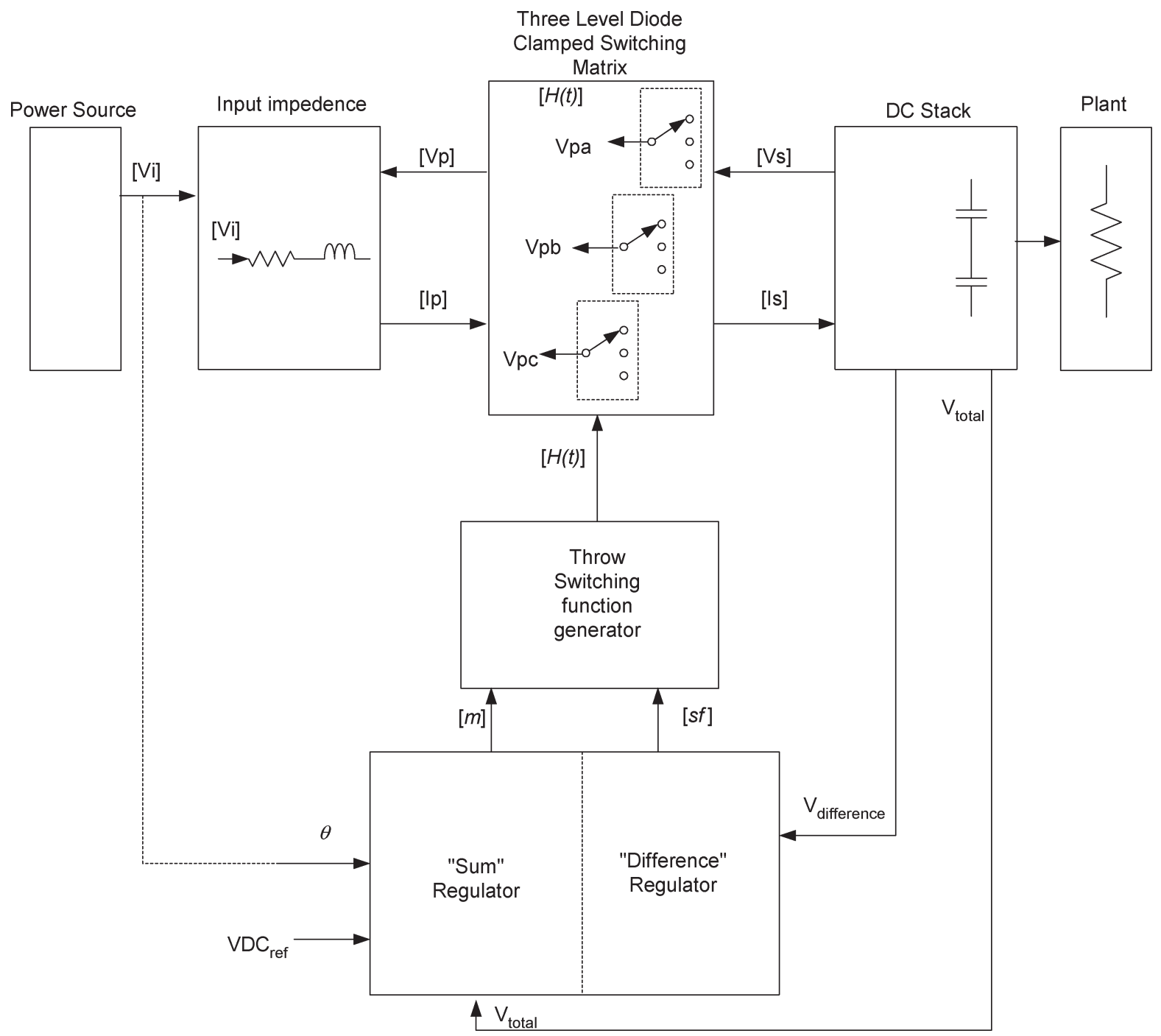

Fig. 1. Block diagram of a generalized multilevel diode-clamped rectifier system.

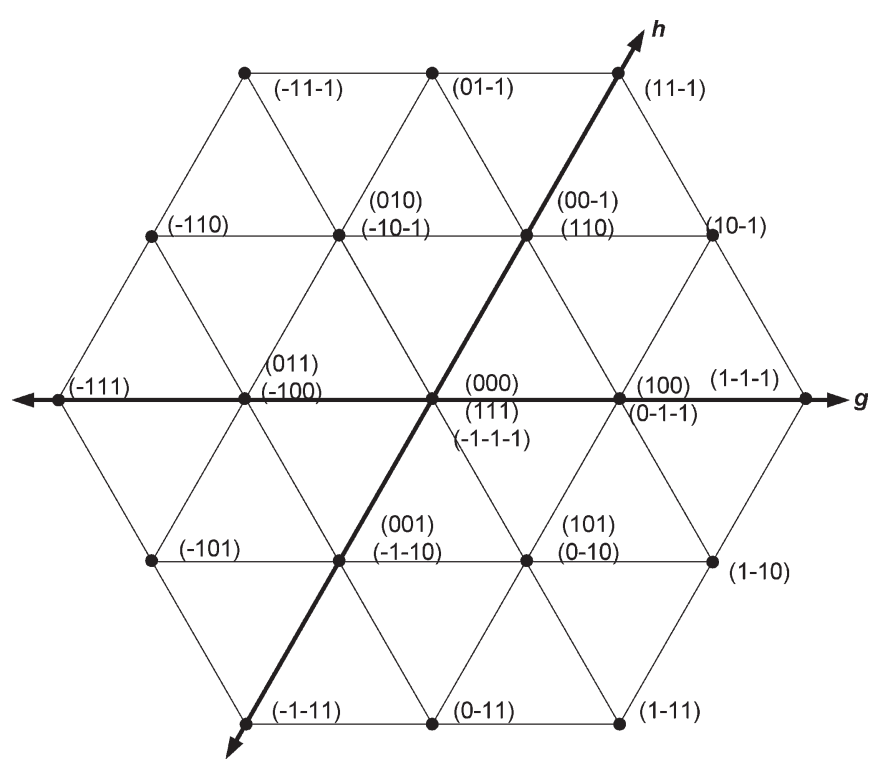

Fig. 2. Representation of the switching states of a three-level converter in the $\mathrm{g}-\mathrm{h}$ plane.
It may be noted from the figure that switching state redundancies appear on the inner hexagon, where two switching states are available for each position. Furthermore, these redundant states on the inner hexagon may be grouped into two subsets, each representing power transfer into one of the two dc buses constituting the stack. The ratio of distribution of duty cycles between the two possible subsets may be represented by a continuous "sharing function" $s f_{1}^{1}$. The average value of the sharing function is nominally 0.5 , representing equal power drawn from the two dc buses. However, by perturbing the sharing function, the relative distribution of power drawn from the dc buses may be varied. This is the basis of the proposed control approach.

A more detailed block diagram of the proposed neutral-point controller for a three-level rectifier is illustrated in Fig. 3. The design of the regulator follows two steps. First, the input-output relationship between the $s f_{1}^{1}$ and the neutralpoint current injection $I_{0}^{\mathrm{AVG}}$ is determined as a function of operating conditions such as modulation level, output current, and power factor. This nonlinear function is then linearized at the steady-state operating condition to obtain an input-output 


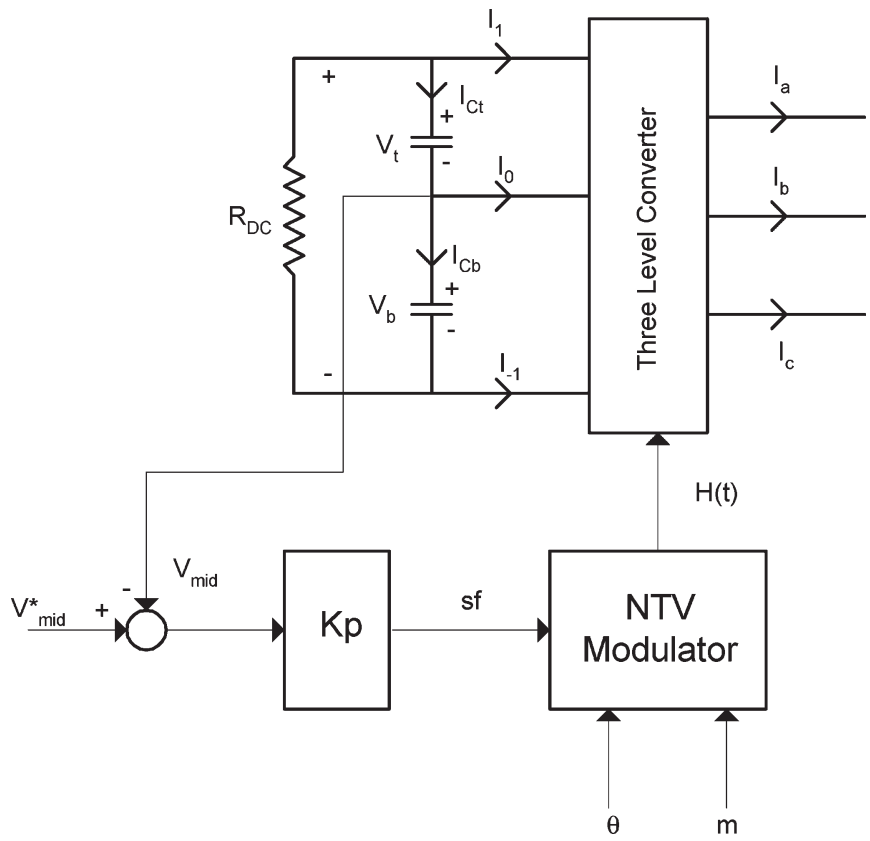

Fig. 3. Block diagram of neutral-point regulator using control of sharing functions $\left(I_{a}, I_{b}\right.$, and $I_{c}$ are ac line currents).

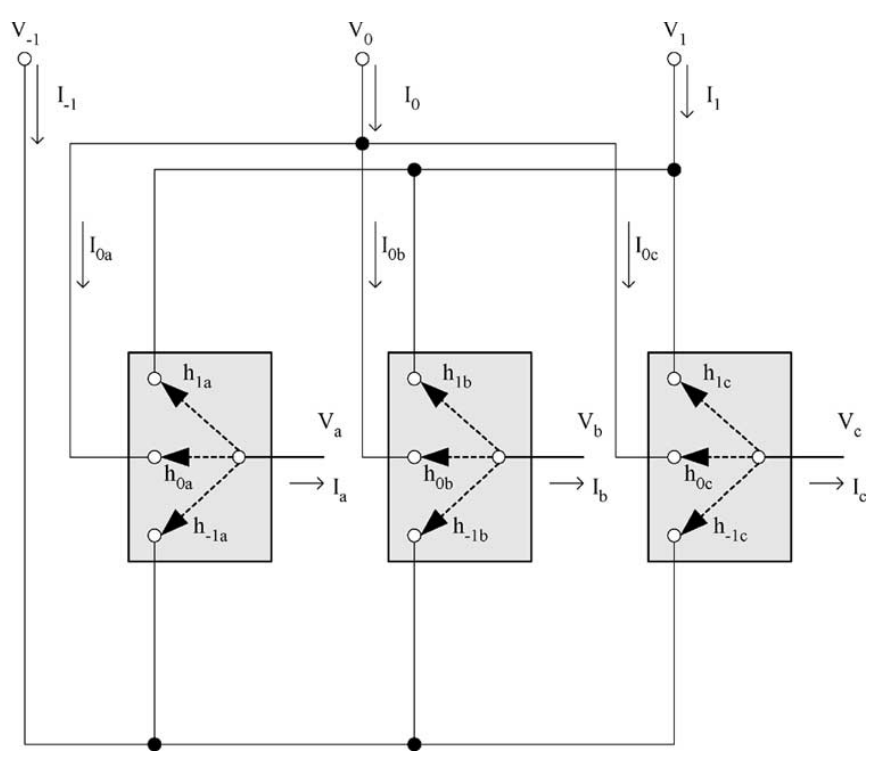

Fig. 4. Simplified equivalent circuit of a three-level rectifier using single-pole triple-throw switches.

transfer function and further used for developing a controller for the midpoint voltage.

\section{Modeling Neutral-Point CurRent Injection}

Three-level converters can be represented by an equivalent circuit containing three single-pole triple-throw switches as shown in Fig. 4. Here, each of the three throws for the switches is connected to a dc-bus level-top $\left(V_{1}\right)$, middle $\left(V_{0}\right)$, and bottom $\left(V_{-1}\right)$. The switching action of each of the throws can be represented by their respective switching functions $\left(h_{0 a}\right.$, $h_{1 a}$, etc.).

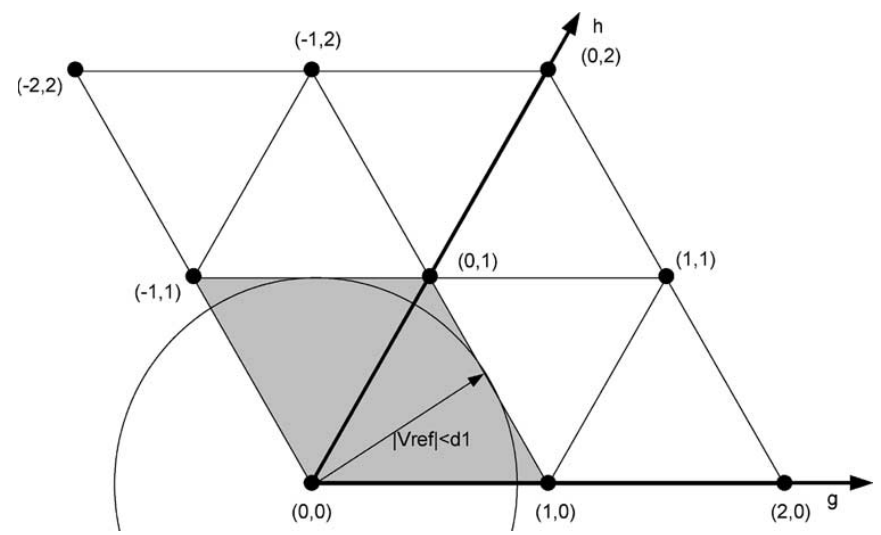

Fig. 5. Mode 1: sectors swept during $120^{\circ}$ excursion of reference vector for modulation index $<0.5$

The following matrix equations that relate dc stack variables to ac output variables can be written for three-level converters [8]:

$$
\begin{aligned}
\left(\begin{array}{l}
V_{a}(t) \\
V_{b}(t) \\
V_{c}(t)
\end{array}\right) & =\left(\begin{array}{lll}
h_{1 a}(t) & h_{0 a}(t) & h_{-1 a}(t) \\
h_{1 b}(t) & h_{0 b}(t) & h_{-1 b}(t) \\
h_{1 c}(t) & h_{0 c}(t) & h_{-1 c}(t)
\end{array}\right)\left(\begin{array}{l}
V_{1} \\
V_{0} \\
V_{-1}
\end{array}\right) \\
\left(\begin{array}{l}
I_{1}(t) \\
I_{0}(t) \\
I_{-1}(t)
\end{array}\right) & =\left(\begin{array}{lll}
h_{1 a}(t) & h_{1 b}(t) & h_{1 c}(t) \\
h_{0 a}(t) & h_{0 b}(t) & h_{0 c}(t) \\
h_{-1 a}(t) & h_{-1 b}(t) & h_{-1 c}(t)
\end{array}\right)\left(\begin{array}{l}
I_{a}(t) \\
I_{b}(t) \\
I_{c}(t)
\end{array}\right) .
\end{aligned}
$$

The neutral-point current is given by the second row of the second equation of the set in (1). As the switching functions assume values of 0 and 1 at the switching frequency, the neutral-point current contains switching frequency content as well as low-frequency (primarily triplen harmonics) content when traditional space vector modulators are used [9]. Pertinent low-frequency information can be extracted from (1) by using generalized averaging techniques [10]. Thus, each element $h_{i j}$ is replaced by its averaged equivalent $m_{i j}$ as

$$
m_{i j}(\tau)=\frac{1}{T} \int_{\tau-T}^{\tau} h_{i j}(t) d t
$$

By further integrating the appropriate high-frequency averaged stack current over a period of the fundamental waveform, the net average neutral-point current can be obtained as

$I_{0}^{\mathrm{AVG}}=\frac{1}{2 \pi} \int_{0}^{2 \pi}\left(m_{0 a}(t) I_{a}(t)+m_{0 b}(t) I_{b}(t)+m_{0 c}(t) I_{c}(t)\right) d t$.

The mathematical model for space-vector modulation that uses the $\{\mathrm{g}, \mathrm{h}\}$ coordinate system developed in [4] is applied for this purpose. In this coordinate system, the triangular regions swept by the reference voltage vector during a $120^{\circ}$ interval are illustrated in Figs. 5-7. It may be noted that there are three distinct modes of operation, leading to three unique patterns of triangular regions chosen, depending on the magnitude of the reference vector. 


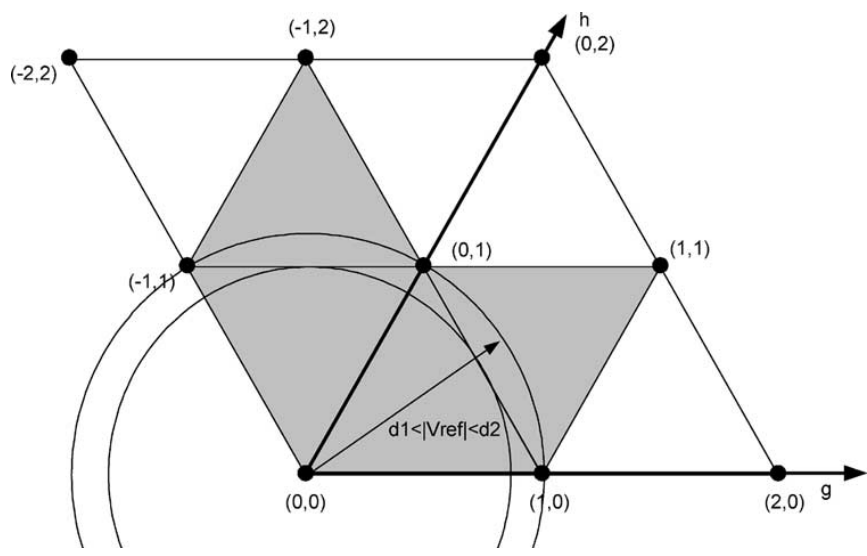

Fig. 6. Mode 2: sectors swept during $120^{\circ}$ excursion of reference vector for $0.5<$ modulation index $<0.57$.

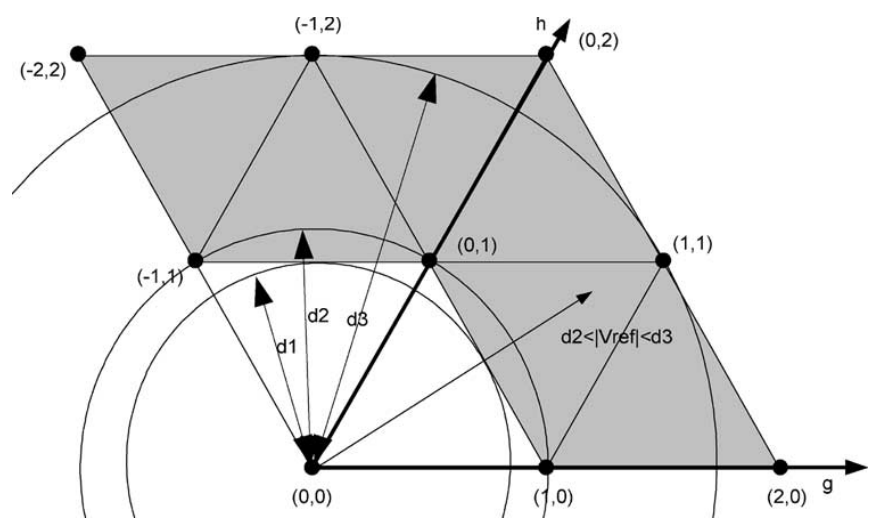

Fig. 7. Mode 3: sectors swept during $120^{\circ}$ excursion of reference vector for $0.57<$ modulation index $<1$.

The limits on the magnitude of the reference voltage vector that represent the boundary between these modes may be computed as $d_{1}, d_{2}$, and $d_{3}$ using geometrical constraints as

$$
d_{1}=\frac{\sqrt{3}}{2} \quad d_{2}=1 \quad d_{3}=\frac{2 \sqrt{3}}{2}
$$

where the three modes are defined as

Mode 1: $0<\mid$ Vref $\mid<d_{1}$;

Mode 2: $d_{1}<\mid$ Vref $\mid<d_{2}$;

Mode 3: $d_{2}<\mid$ Vref $\mid<d_{3}$.

These boundaries are shown in Fig. 7. The largest output voltage is produced when the modulation index is unity, which corresponds to a peak value of $\mid$ Vre $f \mid=d_{3}$. Thus, the boundaries in (4) can be expressed in terms of the modulation index $m$ by rescaling, i.e.,

$$
d_{1}=\frac{1}{2} \quad d_{2}=\frac{2}{\sqrt{3}} \quad d_{3}=1
$$

Within each sector, averaged duty cycles can be derived for each of the three positions that form the three vertices of the sector, with the remaining positions assigned zero duty cycles. Expressions can be written for the averaged throw functions within each sector as a summation of duty cycles of states that connect appropriate dc stack to the proper pole. For example, in Mode 3 operation, when the reference vector is in the sector formed by [(1-1-1), (10-1), (100, 0-1-1)], averaged modulation functions become

$$
\begin{aligned}
& m_{0 a}(t)=d^{0-1-1}(t) \\
& m_{0 b}(t)=d^{100}(t)+d^{10-1}(t) \\
& m_{0 c}(t)=d^{100}(t) .
\end{aligned}
$$

Thus, within each sector, an expression for the various $m_{i j}$ and hence the stack currents can be written explicitly, leading to piecewise linear functions that describe their time-domain behavior. Therefore, the space vector modulation strategy [4] provides unique continuous functions for the low-frequency components of the injected currents in each of the triangular regions.

If the output currents are assumed to be sinusoidal with one per unit amplitude, the average current injection into the midpoint of the stack can be computed as a function of the modulation index $m$, the power factor $\phi$, and the sharing function as

$$
\begin{aligned}
I_{0}^{\mathrm{AVG}}= & \sqrt{3} m\left(1-2 s f_{1}^{1}\right) \cos (\phi) \\
= & \frac{-1}{2 \pi} \cos (\phi) \\
& \times\left[3\left(2 s f_{1}^{1}-1\right)\right. \\
& \times\left[3\left(m \cos \left(2 \beta_{1}\right)+2 \sin \left(\beta_{1}\right)\right)\right. \\
\left.\left.\quad-\sqrt{3}\left(2 \cos \left(\beta_{1}\right)-m\left(4 \beta_{1}+\sin \left(2 \beta_{1}\right)\right)\right)\right]\right] & \text { mode } 1 \\
=\frac{-1}{2 \pi} \cos (\phi)\left[3\left(2 s f_{1}^{1}-1\right)\right. & \quad \times\left[m+2 \sqrt{3} m \beta_{2}-2 \sqrt{3} \cos \left(\beta_{2}\right)\right. \\
& \left.\left.\quad+2 m \cos \left(2 \beta_{2}\right)-2 \sin \left(\beta_{2}\right)\right]\right] \text { mode 3 }
\end{aligned}
$$

where $\beta_{1}=\sin ^{-1}[1 / 2 m]-\pi / 3$ and $\beta_{2}=-\sin ^{-1}[1 / 2 m]+$ $\pi / 3$. Similar expressions can also be derived for the average currents drawn from the top $\left(I_{1}^{\mathrm{AVG}}\right)$ and bottom $\left(I_{-1}^{\mathrm{AVG}}\right)$ levels of the stack.

\section{Small-Signal Model of Neutral-Point CURRENT INJECTION}

From the equivalent circuit in Fig. 1, the dynamics of the unbalance voltage $V_{m}=\left(V_{t}-V_{b}\right)$ may be expressed as

$$
\frac{d V_{m}^{\mathrm{AVG}}}{d t}=\frac{1}{C}\left(I_{0}^{\mathrm{AVG}}\right)
$$

where

$$
I_{0}^{\mathrm{AVG}}=f\left(m, \phi, s f_{1}^{1}\right)
$$

as described in (2). The function $f$ takes different forms depending on the amplitude of the reference vector. The 
small-signal behavior of this system with respect to the control input being the sharing function within each mode may be characterized as

$$
C \frac{d \tilde{V}_{m}^{\mathrm{AVG}}}{d t}=\frac{\partial f\left(m, \phi, s f_{1}^{1}\right)}{\partial s f_{1}^{1}} s \tilde{f}_{1}^{1}
$$

where $\partial I_{0}^{\mathrm{AVG}} / \partial s f_{1}^{1}$ is expressed as shown in (11) at the bottom of the page.

From (10) and (11), it is clear that the small signal model for the system behaves as a pure integrator, with a gain that depends on the partial derivatives expressed by (11). Thus, the system will have zero steady state error dynamics with only a proportional controller with gain $K_{p}$. It is seen that the forward gain is dependent upon the magnitude and phase of the reference vector, and the sign is dependent on the phase. Thus, a priori knowledge of the power delivery mode (motoring or regenerating) is required to design a stable compensator. The closed-loop transfer function between the command voltage and actual imbalance may be expressed as

$$
\frac{V_{m}^{f}}{V_{m}^{*}}(s)=\frac{1}{1+\frac{s}{K p \frac{\partial f}{\partial s f_{1}^{1}}}} .
$$

The closed-loop system transfer function is that of a low-pass filter. Clearly, the bandwidth of the neutral-point regulator can be improved by increasing the proportional gain of the compensator. If the current phase angle is known, the compensator gain can be dynamically scheduled to compensate for the variations in the system forward gain, thus ensuring uniform bandwidth for various operating points.

\section{Simulation Results}

A MATLAB Simulink model of a three-level converter using space vector modulation was developed and operated in rectifier mode [11]. The operating parameters are shown in Table I. Extensive simulations were conducted to verify the performance of the regulator and the rectifier system at a wide variety of operating conditions. Selected waveforms from the computer simulation are illustrated in Figs. 8-10, indicating the performance of the system as desired.

\section{HARDWARE RESULTS}

A hardware prototype was built to verify the analysis and simulation results obtained using the closed-loop neutral-point
TABLE I

Simulation Parameters For A Three-LeVel Rectifier System

\begin{tabular}{ccc}
\hline \hline Parameter & $\begin{array}{c}\text { Simulation } \\
\text { Parameter Value }\end{array}$ & $\begin{array}{c}\text { Hardware } \\
\text { Component Value }\end{array}$ \\
\hline \hline Line Inductance & $300 \mathrm{uH}$ & $12 \mathrm{mH}$ \\
DC Bus Resistance & $19 \Omega$ & $93 \Omega$ \\
DC Link Voltage & $400 \mathrm{~V}$ & $400 \mathrm{~V}$ \\
Line current & $21 \mathrm{~A}$ & $5 \mathrm{~A}$ \\
DC bus capacitance & $44 \mu \mathrm{F}$ & $90 \mu \mathrm{F}$ \\
Switching frequency & $20 \mathrm{kHz}$ & $5 \mathrm{kHz}$ \\
Line Voltage & $460 \mathrm{~V}$ & $230 \mathrm{~V}$ \\
\end{tabular}

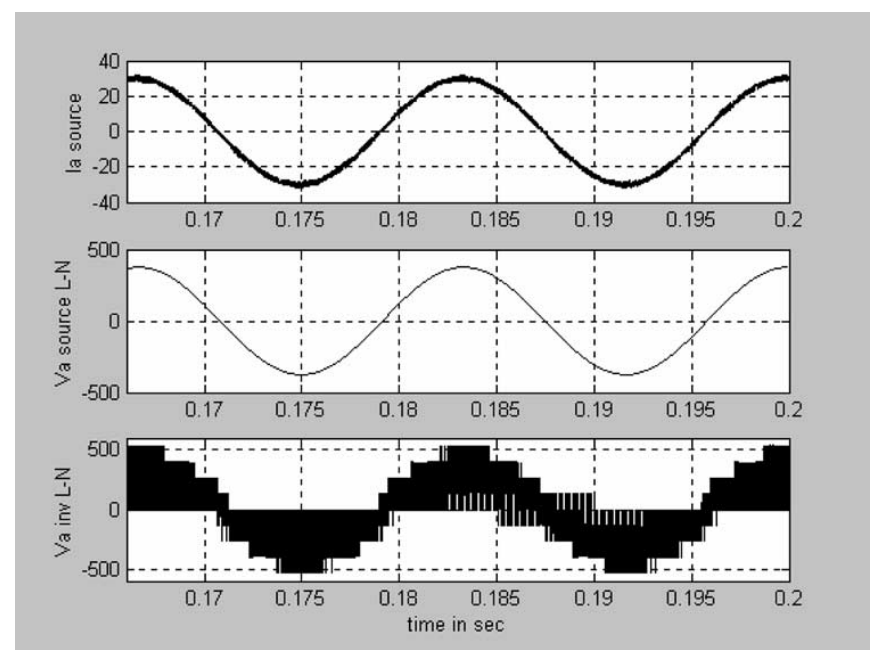

Fig. 8. Simulation waveforms for rectifier system showing the input waveforms. Trace 1: input line current; trace 2: source line neutral; trace 3: rectifier pole-neutral voltage.

regulator (Fig. 11). The prototype used nine dual IGBT devices and unlytic capacitors interconnected with laminated bus planes to create a three-phase three-level inverter power platform. The component values used in the prototype are shown in Table I, in the third column. The control algorithm has been implemented on a general-purpose real-time control prototyping platform. This platform is based on a TI TMS320C31 Digital Signal Processor and a Xilinx Spartan series field programmable gate array for software and logic-based algorithm implementation. The DSP was used to synthesize the reference waveforms and to implement the neutral-point voltage regulator. PWM control generation, dead-time restriction, and protection functions are implemented on the FPGA. High-power signal scaling and

$$
\begin{array}{rlr}
\frac{\partial I_{0}^{\mathrm{AVG}}}{\partial s f_{1}^{1}} & =-2 \sqrt{3} m \cos (\phi) & \text { mode } 1 \\
& =-3 \cos (\phi)\left[\frac{4 \sqrt{3} m \beta_{1}+2 \sqrt{3} \cos \beta_{1}-3 m \cos \left(2 \beta_{1}\right)-6 \sin \beta_{1}+\sqrt{3} m \sin \left(2 \beta_{1}\right)}{\pi}\right] & \text { mode 2 } \\
& =3 \cos (\phi)\left[\frac{m+2 \sqrt{3} m \beta_{2}-2 \sqrt{3} \cos \beta_{2}+2 m \cos \left(2 \beta_{2}\right)-2 \sin \beta_{2}}{\pi}\right] & \text { mode 3 }
\end{array}
$$




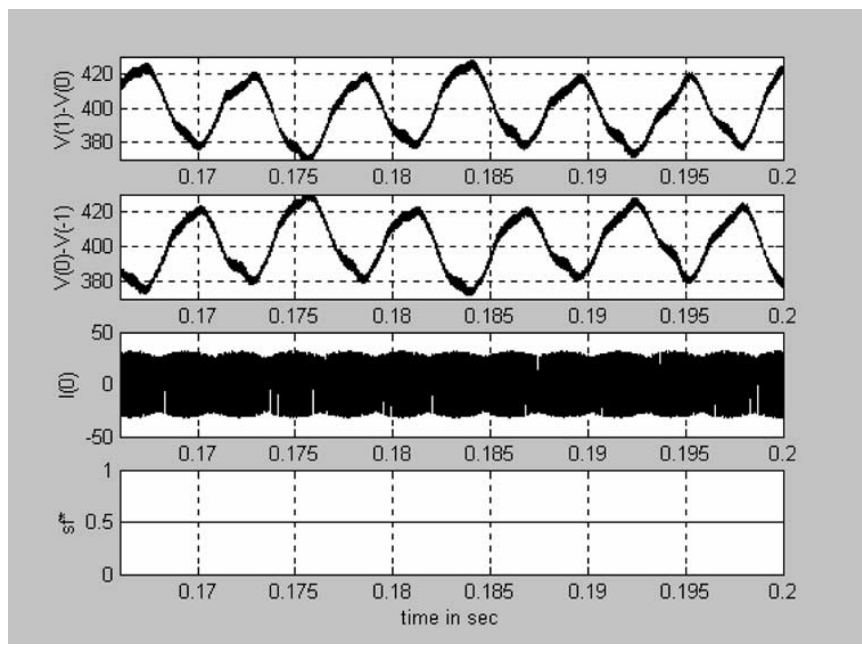

Fig. 9. Simulation waveforms for the rectifier system showing dc-link voltages without closed-loop neutral-point regulation. Trace 1: top bus; trace 2: bottom bus; trace 3: neutral-point current; trace 4: sharing function.

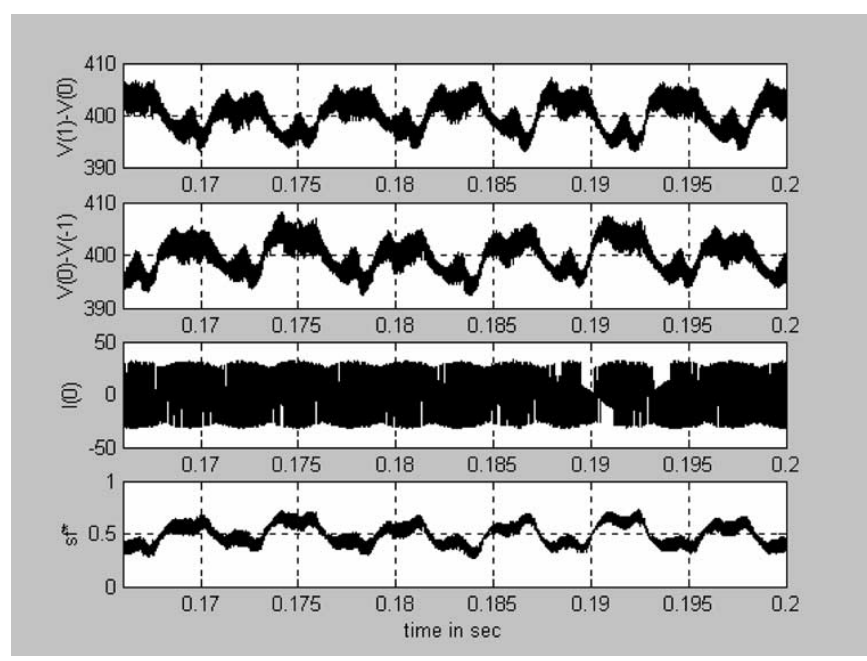

Fig. 10. Simulation waveforms for rectifier system showing dc link voltages with closed-loop regulation. Trace 1: top bus; trace 2: bottom bus; trace 3: neutral-point current; trace 4: sharing function.

conditioning have been implemented on a separate sensor board that interfaces to the control prototyping platform.

Key operating waveforms of the active rectifier operation at steady state, viz., Pole A-Pole B voltage and source A-B line-line voltage, are shown in Fig. 12. The operation of the rectifier at start up is shown in Fig. 13, where the dc bus voltage, the current reference, the source line-line voltage, and the line current are shown. Unity power factor operation can be verified by observing the current waveform before and after the rectifier is turned on, at the midpoint of the horizontal axis.

The closed-loop gain of the neutral-point regulator shown in Fig. 3 was measured using a frequency response analyzer [12]. The predicted closed-loop gain from the analytical model developed in Section IV and the measured closed-loop gain are shown in Figs. 14 and 15. The agreements between the small signal model and the measurements are readily evident from the figures.

In order to demonstrate the need for functional neutralpoint regulator for rectifier to ensure proper operation, the

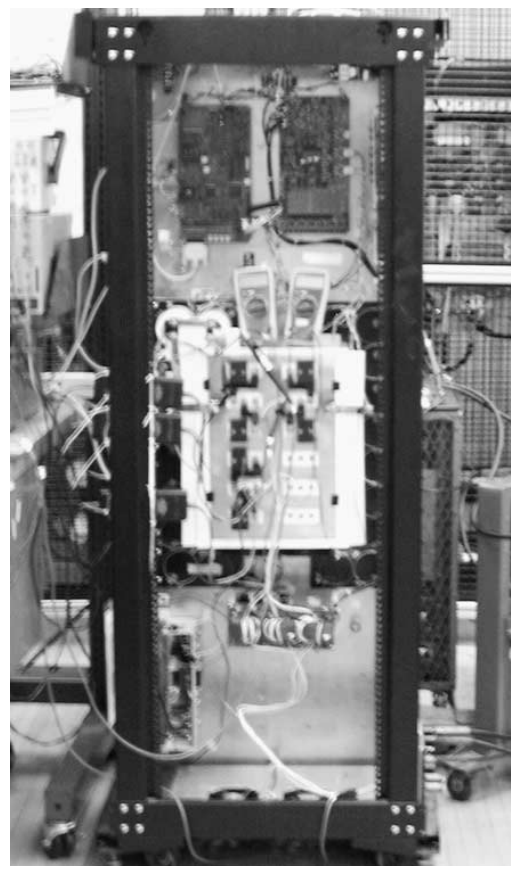

Fig. 11. Photograph of the prototype of three-level converter system.

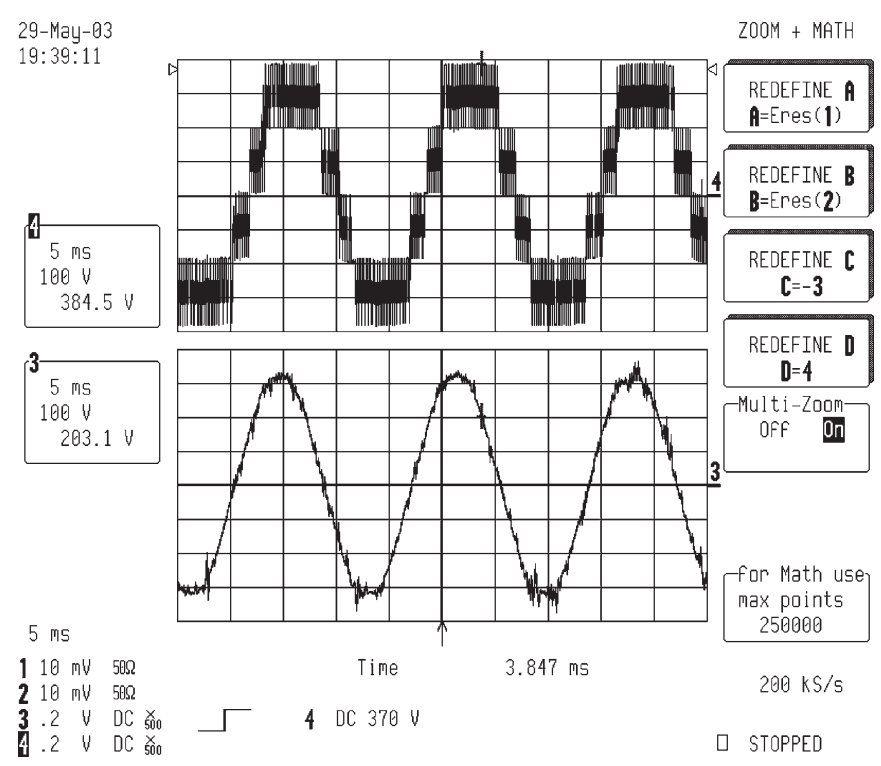

Fig. 12. Key steady state operating waveforms of the active rectifier (Top) Pole A-Pole B voltage. (Bottom) Source A-B line-line voltage.

rectifier system was run with and without a neutral-point regulator. The results from these tests are illustrated in Figs. 16 and 17. When the rectifier is enabled, without the regulator, one of the dc buses collapses while the other gets charged to the total value (Fig. 16). Conversely, even if one of the buses is initially completely discharged, the action of the neutral-point regulator brings the two buses into balance (Fig. 17). This test was carried out at a lower dc bus voltage, as abnormal behavior was expected.

In addition to providing appropriate balancing of the neutralpoint potential to ensure proper operation of three-level rectifiers, the proposed neutral-point regulator also reduces the triplen harmonic injection into the neutral point of the dc bus 


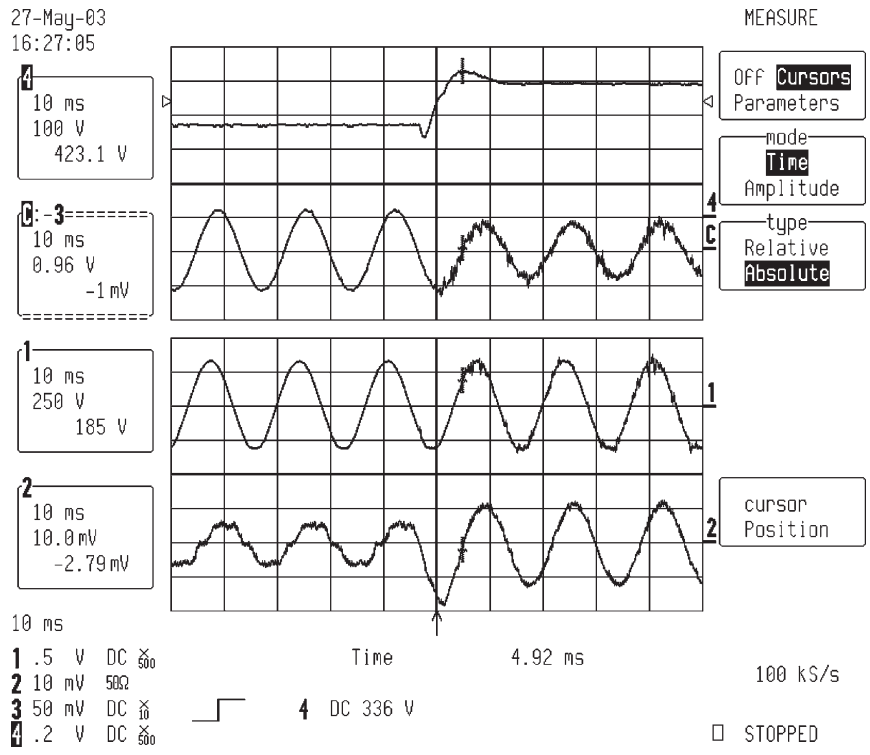

Fig. 13. Startup of active rectifier. Ch. 1: A-B line voltage; Ch 2: line current (5 A/division); Ch C: current reference; Ch 4: dc-bus voltage.

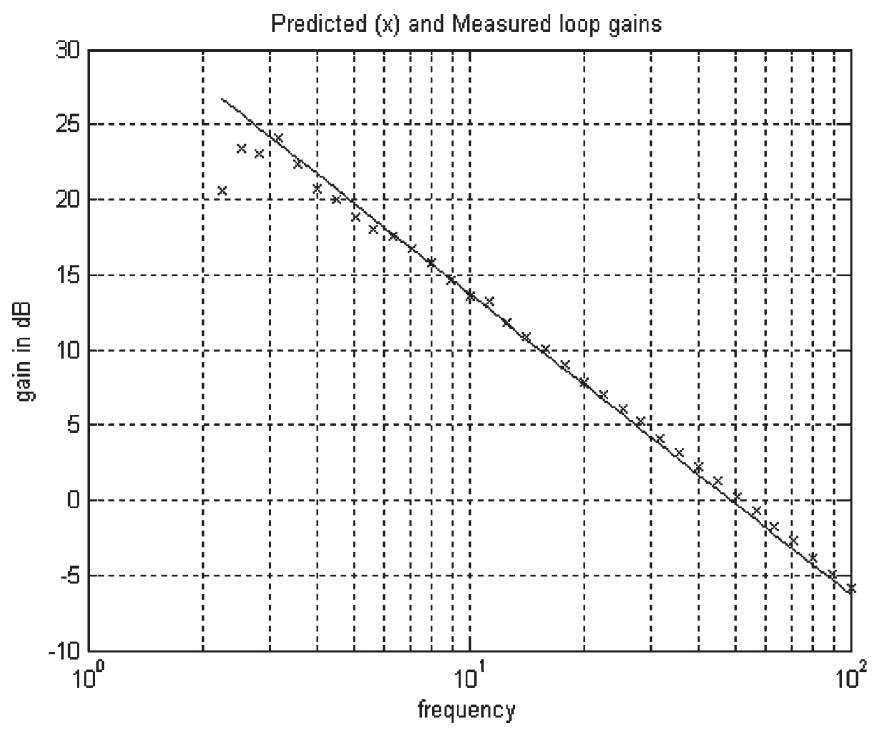

Fig. 14. Predicted and measured loop gain (magnitude) of the neutral-point regulator loop.

stack. This not only reduces the ac voltage variation of the neutral point but also reduces the ripple current loading of the dc bus capacitor. This allows the use of a smaller dc bus capacitor for the dc bus. This improvement obtained using the regulator can be seen in Figs. 18 and 19. In these figures, the phase current and the filtered neutral-point currents with and without the proposed closed-loop regulator are shown. A reduction of third harmonic current and a net reduction of the peak-to-peak current are observed from the figures. A reduction in third harmonic amplitude by a factor of three was measured using a spectral analysis of the waveform as shown in Figs. 20 and 21.

The worst case rms neutral-point current can be shown to be about $70 \%$ of the output current of the converter [13]. While the simulated and constructed systems were based on film capacitors, most traditional converters use aluminum electrolytic cans

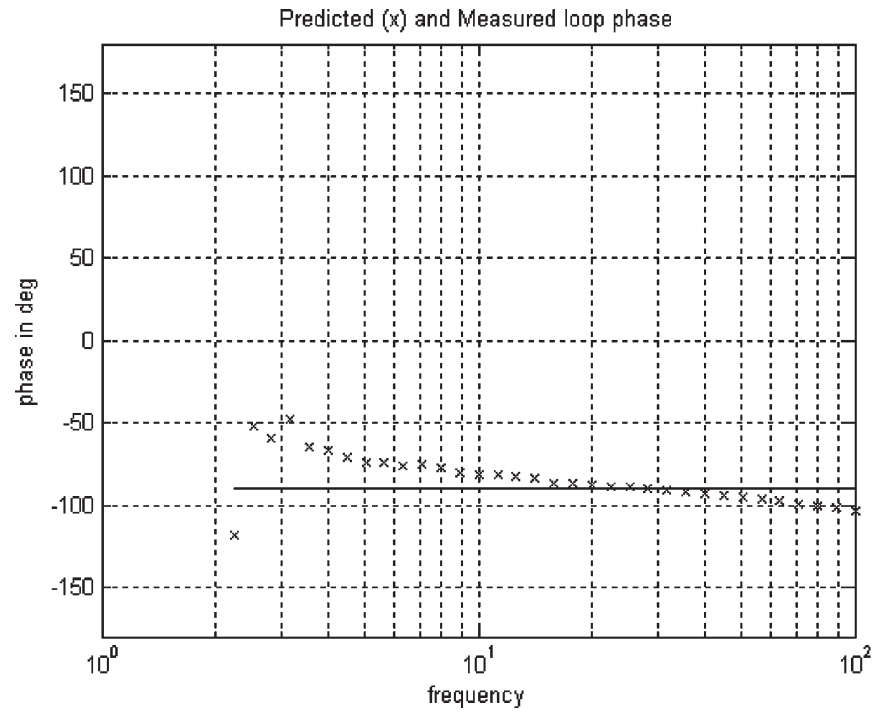

Fig. 15. Predicted and measured loop gain (phase) of the neutral-point regulator loop.

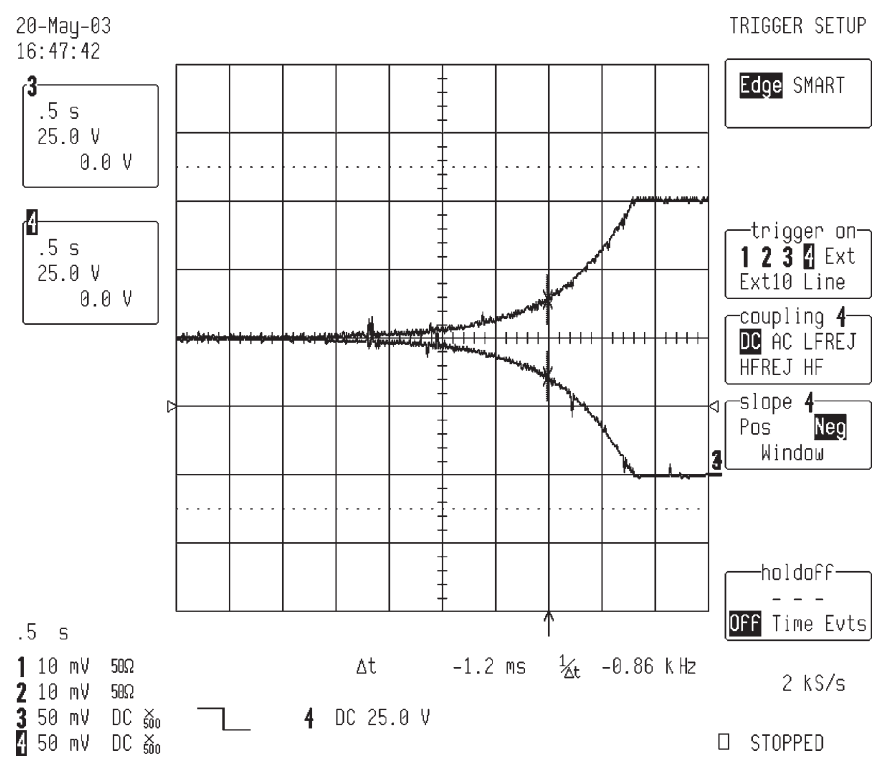

Fig. 16. Collapsing neutral-point voltage without regulator. Ch 3: upper dc-bus voltage; Ch 4: lower dc-bus voltage.

for dc link capacitance. For electrolytic capacitors, the allowable low-frequency current rating is far lower than the rating at higher frequencies. Thus, the third harmonic neutral-point current becomes the determining factor for sizing the capacitor bank for three-level active rectifiers as its frequency is 150 or $180 \mathrm{~Hz}$. Parallel electrolytic cans at the appropriate voltage rating are added until the ripple rating is adequately satisfied. The threefold reduction in the neutral-point current due to the closed-loop regulator will directly reduce the number of parallel cans, leading to a capacitor bank that is one third the size.

\section{CONCLUSION}

This paper proposes a neutral-point voltage regulator for a three-level diode-clamped rectifier that uses a fast space-vector modulator in conjunction with a sharing function controller. 


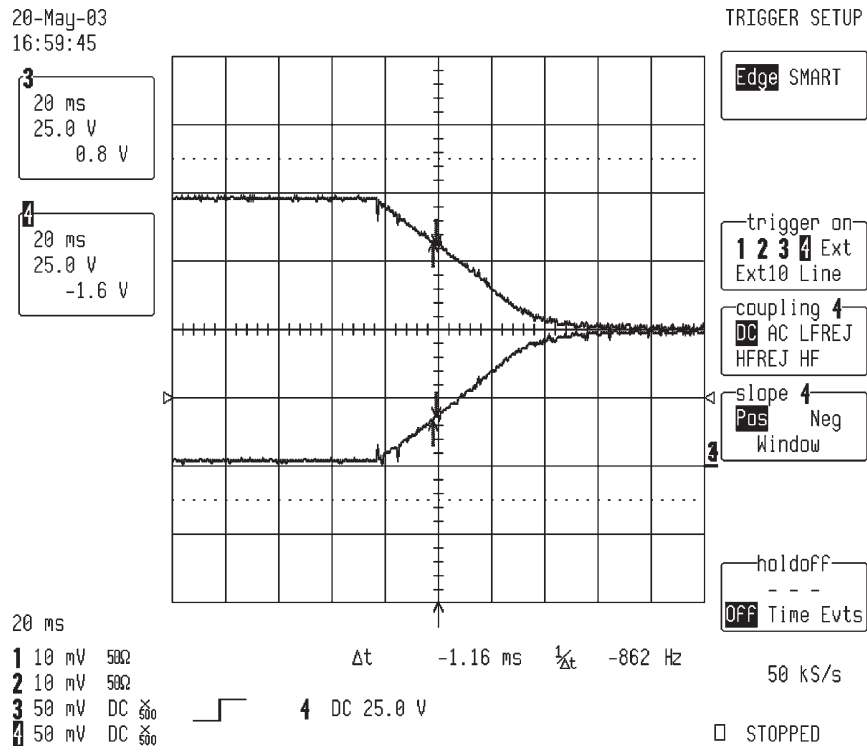

Fig. 17. Converging neutral-point voltage with regulator. Ch 3: upper dc-bus voltage. Ch 4: lower dc-bus voltage.
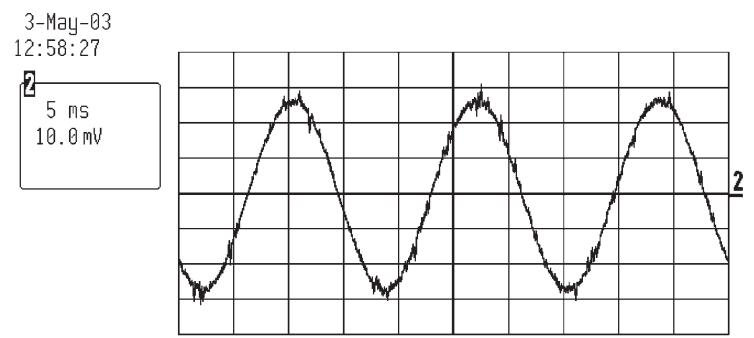

$\left[\begin{array}{l}\text { ii: } \operatorname{Eres}(1)=== \\ 5 \mathrm{~ms} \\ 2.0 \mathrm{mV} \\ \\ =========-\end{array}\right]$

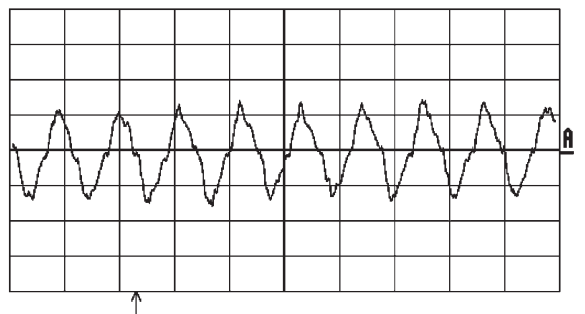

5 mS

$200 \mathrm{kS} / \mathrm{s}$

$110 \mathrm{ml} 50 \Omega$

Q $10 \mathrm{~mW} 588$

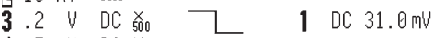

$4.5 \cup \quad D C \times$

口 STOPPED

Fig. 18. Phase current (Ch 2, 2 A/division) and the filtered neutral-point currents (Ch A, $1 \mathrm{~A} /$ division), no regulation.

This combined control approach does not compromise the dc bus voltage regulation or the low THD unity power factor input current synthesis function while maintaining tight regulation of the neutral-point voltage even with a small dc-link capacitance. The sharing function is used as a control handle to vary the ratio of distribution of duty cycles over the two redundant states available on the inner hexagons of the state plane. Closed-form expressions are presented for the neutral-point current injection as a function of the modulation index, the power factor, and the sharing function variable. Similar expressions may also be derived for the total dc bus current injection. Three distinct operating modes are identified depending on the amplitude of the reference vector and the corresponding expressions are shown. By analyzing small signal models developed using these closed-form expressions, closed-loop compensators may

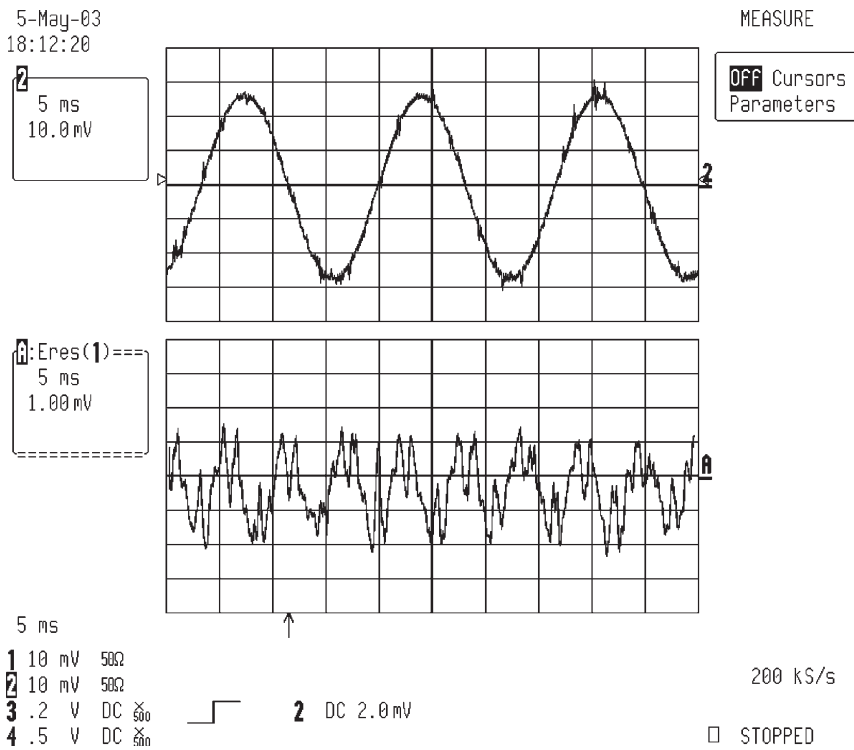

Fig. 19. Phase current (Ch 2, 2 A/division) and the filtered neutral-point currents (Ch A, 0.5 A/division), with regulation.

Date: 05-05-03 Time: 06:33:00 PM

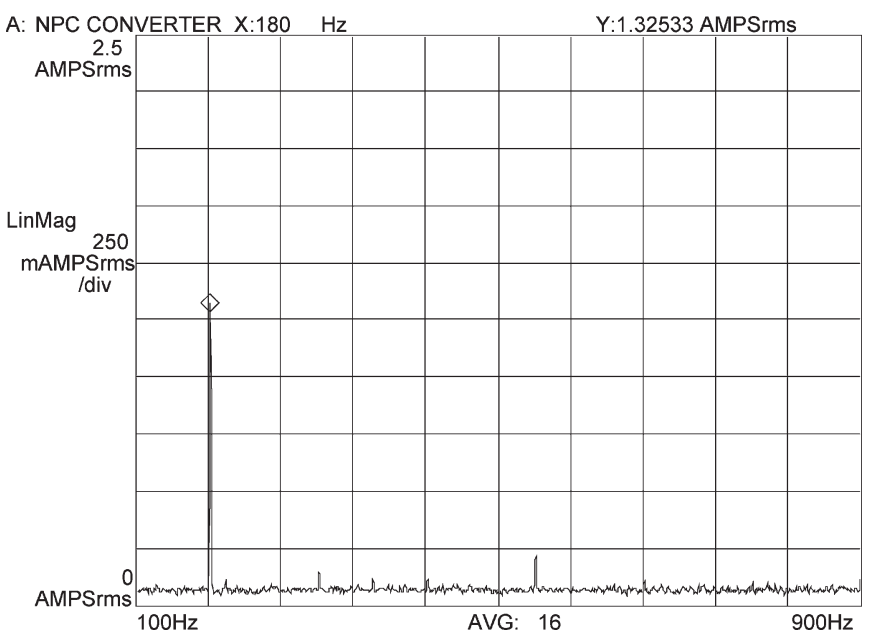

Fig. 20. Measured spectrum of neutral-point current without neutral-point regulation.

be designed, which provide excellent performance and stability for all three operating modes.

The traditional NTV method uses the nearest three vectors to synthesize the output voltage reference and alternates the redundant states for capacitor voltage balance. Thus, the duty cycle of the redundant vector is equally divided among available redundant states. This method does not utilize the degree of freedom provided by the redundancy as the sharing function is fixed at 0.5 , which is a subset of the closed-loop controller with zero proportional gain. Comparing the operation of the closed-loop regulator with the traditional NTV modulator by simulation (Figs. 8 and 9), hardware oscilloscope measurement (Figs. 18 and 19), and hardware spectrum analyzer measurement (Figs. 20 and 21), a significant improvement is seen in the third harmonic current into the neutral point when the regulator is used, and this leads to a definitive reduction in the required dc bus capacitance. Other methods have been proposed [14] 


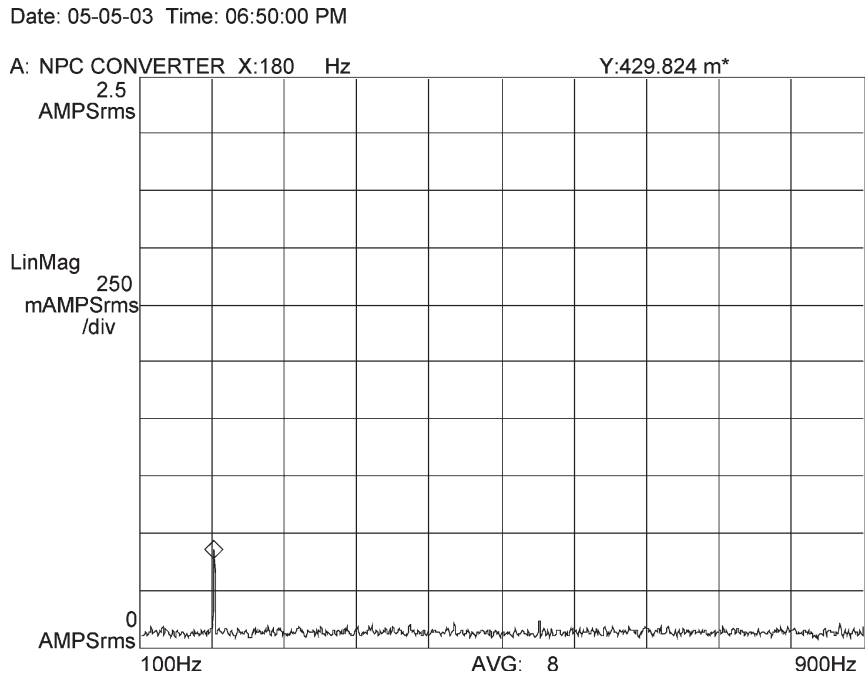

Fig. 21. Measured spectrum of neutral-point current with neutral-point regulation.

that use redundancy at each switching instant to balance the capacitors. These methods fall into the category of hysteretic or bang-bang control as the choice of redundant state is directly affected at every switching instant by the capacitor voltage balance. In these methods, the sharing function can change at the switching frequency, rendering averaging techniques unusable; hence, they are considered to be outside the scope of this work.

A detailed computer simulation of a three-level rectifier with very modest dc bus capacitance is implemented in MATLAB Simulink and neutral-point voltage waveforms are presented. The functionality of the regulator and the small signal model has been verified using a hardware prototype using steady state and transient measurements.

The proposed strategy has been extended to sinusoidal PWM strategies with multiple carriers and to other space vector modulation schemes producing effective neutral-point regulators, and these results are available. The novel concept of controlling redundant state choices via a continuous sharing function, and then developing small signal models for closed-loop regulators with this sharing function as the control variable, can also be applied to regulate other system quantities.

\section{ACKNOWLEDGMENT}

The authors wish to acknowledge the contributions of R. Fons of DRS Power and Control Technologies toward the development of the phase-locked loop algorithm used for the active rectifier.

\section{REFERENCES}

[1] B. P. Schmitt and R. Sommer, "Retrofit of fixed speed induction motors with medium voltage drive converters using NPC three-level inverter high-voltage IGBT based topology," in Proc. IEEE Int. Symp. Industrial Electronics, Pusan, Korea, 2001, vol. 2, pp. 746-751.

[2] P. K. Steimer, J. K. Steinke, and H. E. Gruning, "A reliable, interfacefriendly medium voltage drive based on the robust IGCT and DTC technologies," in Conf. Rec. IEEE-IAS Аnпи. Meeting, Phoenix, AZ, Oct. 1999, vol. 3, pp. 1505-1512.
[3] G. Carrara, S. Gardella, M. Marchesoni, R. Salutari, and G. Sciutto, "A new multilevel PWM method: A theoretical analysis," IEEE Trans. Power Electron., vol. 7, no. 3, pp. 497-505, Jul. 1992.

[4] N. Celanovic and D. Boroyevich, "A fast space-vector modulation algorithm for multilevel three-phase converters," IEEE Trans. Ind. Appl., vol. 37, no. 2, pp. 637-641, Mar./Apr. 2001.

[5] Y.-H. Lee, R.-Y. Kim, and D.-S. Hyun, "A novel SVPWM strategy considering DC-link balancing for a multi-level voltage source inverter," in Proc. IEEE Applied Power Electronics Conf. (APEC), Dallas, TX, 1999, vol. 1, pp. 509-514.

[6] B. McGrath, D. Holmes, and T. Lipo, "Optimised space vector switching sequences for multilevel inverters," in Proc. IEEE Applied Power Electronics Conf. (APEC), Anaheim, CA, 2001, vol. 2, pp. 1123-1129.

[7] P. Loh, G. Holmes, Y. Fukuta, and T. Lipo, "Reduced common mode carrier-based modulation strategies for cascaded multilevel inverters," in Conf. Rec. IEEE-IAS Annu. Meeting, Pittsburgh, PA, Oct. 2002, vol. 3, pp. 2002-2009.

[8] G. Venkataramanan and A. Bendre, "Reciprocity-transposition-based sinusoidal pulsewidth modulation for diode-clamped multilevel converters," IEEE Trans. Ind. Electron., vol. 49, no. 5, pp. 1035-1047, Oct. 2002.

[9] D.-W. Kang, Y.-H. Lee, B.-S. Suh, C.-H. Choi, and D.-S. Hyun, "An improved carrier-based SVPWM method using leg voltage redundancies in generalized cascaded multilevel inverter topology," IEEE Trans. Power Electron., vol. 18, no. 1, pp. 180-187, Jan. 2003.

[10] D. Perreault and G. Verghese, "Time-varying effects and averaging issues in models for current-mode control," IEEE Trans. Power Electron., vol. 12, no. 3, pp. 453-461, May 1997.

[11] Mathworks Product Family Overview. [Online]. Available: http://www. mathworks.com/products/pfo

[12] Users Manual for Venable Model 3120 Frequency Response Analyzer. [Online]. Available: http://www.venable.biz/pr-3120.html

[13] A. Bendre and G. Venkataramanan, "Radial state space vector modulation-A new space vector technique for reducing DC link capacitor harmonic currents in three level converters," in Conf. Rec. IEEE-IAS Аnпи. Meeting, Salt Lake City, UT, Oct. 2003, vol. 1, pp. 684-691.

[14] N. Celanovic and D. Boroyevich, "A comprehensive study of neutral-point voltage balancing problem in three-level neutral-point-clamped voltage source PWM inverters," IEEE Trans. Power Electron., vol. 15, no. 2, pp. 242-249, Mar. 2000.

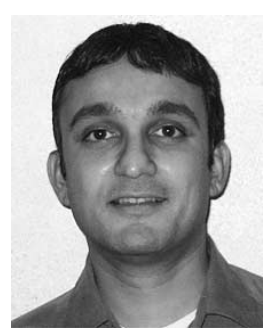

Ashish Bendre (S'02-M'03) received the B.Tech. degree in electrical engineering from the Indian Institute of Technology, Bombay, India in 1990, and the M.S. and Ph.D. degrees in electrical engineering from the University of Wisconsin, Madison, in 1992 and 2003, respectively. He is currently working toward the M.B.A. degree at the University of Chicago, Chicago, IL.

He has over 13 years of industrial power converter design and development experience, primarily at Pillar Technologies and SoftSwitching Technologies. He is currently a Principal Engineer with the Advanced Development Group, DRS Power and Control Technologies, Milwaukee WI, where he conducts research focused on naval power conversion. His primary areas of interest include power electronics and control design for multilevel converters, $\mathrm{dc}-\mathrm{dc}$ converters, and power quality devices.

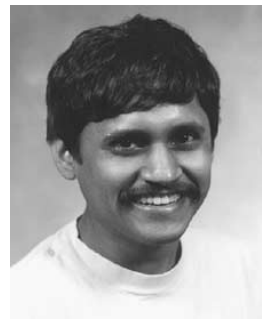

Giri Venkataramanan $\left(\mathrm{S}^{\prime} 86-\mathrm{M}^{\prime} 86\right)$ received the B.E. degree from the Government College of Technology, Coimbatore, India, in 1987, the M.S. degree from the California Institute of Technology, Pasadena, in 1987 and the Ph.D. degree from the University of Wisconsin, Madison, in 1992, all in electrical engineering.

After teaching electrical engineering at Montana State University, Bozeman, he returned to the University of Wisconsin, Madison, as a faculty member in 1999, where he continues to direct research in various areas of electronic power conversion as an Associate Director of the Wisconsin Electric Machines and Power Electronics Consortium (WEMPEC). He holds five U.S. patents and has published a number of technical papers. His interests are in the areas of microgrids, distributed generation, renewable energy systems, matrix and multilevel power converters, and ac power flow control. 